\title{
REVISIÓN DE LA CATEGORÍA «ADVERBIO» EN ESPAÑOL ${ }^{1}$
}

FCO. JAVIER SATORRE GRAU

Universidad de Valencia

1. La consideración del estudio de la lengua como una disciplina científica impone, como una exigencia inexcusable, la necesidad de categorizar sus elementos. La descripción del sistema lingüístico no puede hacerse con rigor sin conocer cuáles son los elementos que la componen.

La necesidad de la clasificación de los elementos de la lengua se sintió desde los orígenes de los estudios gramaticales. Los primitivos griegos formularon una clasificación de las partes de la oración que, con diversas variantes, ha perdurado hasta nosotros, sin que haya parecido especialmente necesaria una revisión crítica.

A fines del siglo XIX se produjo en la linguíistica un cambio radical en el punto de vista desde el que se abordaban los estudios sobre la lengua. La gramática ya no se consideró como un «arte de hablar y escribir correctamente», sino que lo que se pretendía era describir ese sistema de signos e instrumento de comunicación que es la lengua. En este caso, el modelo de investigación ofrecido por las ciencias naturales, desarrollado básicamente a lo largo de los siglos XVIII y XIX, se adoptó como procedimiento válido para poder construir una lingüística «científica». Las ciencias naturales clasifican los seres de la naturaleza por medio de procedimientos taxonómicos. Los elementos categorizados comparten con todos los demás elementos de la categoría las características y propiedades de la clase en la que se incluyen. Cada clase se identifica por una definición, aplicable a todos y cada uno de los elementos que la componen. Así, por ejemplo, la entomología define lo que es un «insecto» como el «artrópodo de respiración traqueal, con el cuerpo dividido distintamente en cabeza, tórax y abdomen, con un par de antenas y tres de patas. Los más tienen uno o

\footnotetext{
${ }^{1}$ Este trabajo se inscribe dentro de los programas de investigación «La norma del español desde el punto de vista historiográfico (ss. XV-XIX)» (referencia: HUM2006-08394/FILO), Ministerio de Educación y Ciencia y FEDER, e «Historia, codificación y fijeza de las locuciones adverbiales en un segmento temporal del español (1492-1596)» (referencia HUM2005-02879/ FILO), Ministerio de Educación y Ciencia.
} 
dos pares de alas y sufren metamorfosis durante el desarrollo». La araña, por mucho que se parezca a los insectos, no pertenecerá a esta clase de animales porque no cumple las condiciones: tiene cuatro pares de patas y no tres. Tener alas o no no es condición necesaria para ser insecto; tener seis patas sí que lo es. En gramática se imita el modelo ofrecido por las ciencias naturales para dotar a la disciplina del rigor necesario para que la descripción de la lengua pueda considerarse una ciencia. Esta descripción exige, como condición necesaria, la clasificación de sus elementos en categorías distintas. No puede describirse un sistema si no se reconocen las unidades que lo conforman. Esto es válido, también, en el caso de las palabras.

La tradición gramatical ha transmitido una serie de términos por medio de los cuales ha querido nombrar las distintas clases de palabras de la lengua:

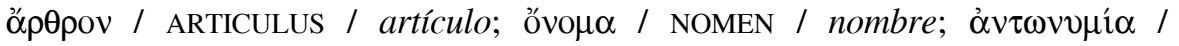
PRONOMEN / pronombre; $\rho \hat{\eta} \mu \alpha$ / VERBUM / verbo; żंi $\rho \rho \eta \mu \alpha$ / ADVERBIUM / ad-

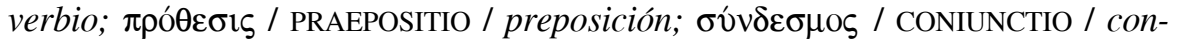
junción. Estos términos, creados por los gramáticos griegos para explicar su propia lengua, fueron adoptados por los romanos, traduciéndolos al latín. Las gramáticas de las lenguas modernas han heredado esta clasificación de las palabras sin discusión previa y sin pararse a comprobar si sus elementos son homogéneos o no.

Las gramáticas griega y latina crearon unas clases de palabras que correspondían a la naturaleza gramatical de estas lenguas. Las gramáticas de las lenguas modernas se han limitado a heredar estas clases de palabras y a adaptar su realidad lingüística a este esquema de categorización, lo que ha originado serios problemas, como observa Bosque ${ }^{2}$. Sin embargo, a pesar de la constatación de que la realidad lingüística no se ajusta al esquema explicativo, se sigue conservando este esquema como si fuera algo intocable.

En tiempos recientes, la teoría del prototipo ha venido a proponer una solución a este callejón sin salida en el que se ha convertido la categorización de las unidades gramaticales. Pero esta teoría, más que proponer un verdadero remedio, ha ofrecido salirse por la tangente obviando el verdadero problema; o mejor dicho, aceptando que el problema no tiene solución y que, como la categorización de los elementos en clases claras y distintas no es posible, tenemos que conformarnos con la aceptación de unas áreas de límites difusos en las que, en torno a unos elementos a los que reconocemos como prototipos de una categoría, se agrupan los elementos que forman parte de ella, más o menos ordenados según la mayor o menor proximidad al prototipo. Así, hay sustantivos que son más sustantivos que otros; verbos que son más verbos que otros y adverbios que son más adverbios que otros.

\footnotetext{
${ }^{2}$ Ignacio Bosque, Las categorías gramaticales. Relaciones y diferencias, Madrid, Síntesis, 1998.
} 
2. Si en algo están de acuerdo todos los que se han dedicado al estudio del adverbio es en que, en esta categoría, se contienen elementos enormemente variados y heterogéneos, de las más diversas procedencias y con diferentes formas, funciones e, incluso, significaciones. Es célebre la afirmación de Karcevskij ${ }^{3}$ de que toda unidad que no pertenece a otra categoría es un adverbio. Algo parecido dice Brøndal $^{4}$, pero insistiendo en que se trata de la clase de palabras más heterogénea y confusa, y con mucho, la más difícil de delimitar y de dividir ${ }^{5}$. El adverbio se nos ofrece, pues, como un gran cajón de sastre donde colocamos todas aquellas unidades que no encajan en las otras categorías. El adverbio español, a pesar de los intentos de definición y clasificación de Alar$\cos ^{6}$, Carbonero Cano ${ }^{7}$, Hallebeek ${ }^{8}$, Álvarez Martínez ${ }^{9}$, González García ${ }^{10}$, etc., sigue siendo un territorio confuso, que pone de manifiesto las dificultades que encuentra la gramática para encontrar orden en una clase de palabras tan heterogénea y poco clara ${ }^{11}$. Bosque ${ }^{12}$ llega a proponer dejar de manejar categorías tan abarcadoras como «adverbio» para poder observar claramente la enorme variedad de elementos que recubren.

El problema es más complejo aún, si tenemos en cuenta la enorme cantidad de unidades pluriverbales que, en español, se comportan como si fueran adverbios (locuciones adverbiales). La misma confusión y heterogeneidad que caracteriza la categoría adverbial afecta a las locuciones adverbiales. Los trabajos que pretenden codificar, registrar y ordenar las locuciones adverbiales del español exigen, para poder trabajar con rigor científico, una base teórica fuerte y clara sobre el adverbio, base que, en la actualidad no existe.

3 S. Karcevskij, «Sur la nature de l'adverbe» [1936], A Prague School Reader in Linguistics, J.A. Vachek Bloomington (ed.), Indiana University Press, 1964, pág. 364.

4 Viggo Brøndal, Les parties du discours, Copenhague, Einar Munksgaard, 1948, pág. 52.

5 Dentro de la tradición gramatical española, P. Domínguez de Rodríguez Pasqués («Morfología y sintaxis del adverbio en -mente», Actas del III Congreso Internacional de Hispanistas, México, El Colegio de México, 1970, pág. 293) representa la opinión de Karcevskij al definir el adverbio como «lo que no es sustantivo, ni adjetivo, ni verbo, ni relacionante». Según esta autora, «no hay parte de la oración que configure un conjunto más caótico que el adverbio».

6 Emilio Alarcos Llorach, «Aditamento, adverbio y cuestiones conexas», Estudios de gramática funcional del español, Madrid, Gredos, 1973, págs. 219-253.

7 Pedro Carbonero Cano, «Criterios para una caracterización funcional de los adverbios», RSEL, 8, 1, 1978, págs. 169-197.

8 J. Hallebeek, «El adverbio. Bosquejo de una posible morfosintaxis del elemento adverbial en español», Dicenda. Cuadernos de filología hispánica, 4, 1985, págs. 35-56.

9 M. Ángeles. Álvarez Martínez, El adverbio, Madrid, Arco/Libros, 1994.

10 Luis González García, El adverbio en español, Universidade da Coruña, 1997.

11 Vid. A. M. Coello Mesa y P. A. Martín Rodríguez, «El adverbio: el problema de su definición y clasificación», Revista de Filología de la Universidad de La Laguna, 21, 2003, págs. 59-67.

12 Ignacio Bosque, Las categorías gramaticales..., op. cit. pág. 127. 
3. En este trabajo pretendo dar respuesta, en la medida de lo posible, a las siguientes preguntas:

— ¿Cómo se ha llegado a la situación actual? ¿Cuáles son los rasgos comunes a todos estos elementos que han permitido a la tradición gramatical incluirlos en una misma categoría? O dicho de otro modo, ¿cómo se ha ido formando la teoría gramatical sobre el adverbio?

- ¿En qué consiste, realmente, la heteregeneidad de los elementos que constituyen la categoría del adverbio en las gramáticas actuales? ¿Cuáles son las diferencias que presentan y de qué entidad, para que nos hagan dudar ahora de que la categorización hecha por nuestros mayores sea la correcta? En otras palabras, ¿qué errores ha cometido la tradición gramatical al elaborar la teoría sobre el adverbio?

— ¿Qué debe entenderse, realmente, por adverbio?

- ¿Cómo podemos ordenar, de manera adecuada y razonable, las unidades que actualmente se agrupan en la categoría llamada «adverbio»?

- ¿La teoría gramatical sobre el adverbio es aplicable también a las locuciones adverbiales?

4. Los gramáticos latinos, imitando a los griegos, dividieron las palabras de su lengua en dos grandes grupos formalmente diferentes: el grupo de las palabras llamadas DECLINABILIA, caracterizadas todas ellas por presentar variaciones flexivas, es decir, mudanzas en sus desinencias, y el de las denominadas INDECLINABILIA, caracterizadas por la ausencia de flexión. Los accidentes gramaticales eran los causantes de la variación de las terminaciones de las palabras declinables: género, número y caso en sustantivos, adjetivos y pronombres; y voz, modo, tiempo, número y persona en los verbos. Las palabras indeclinables no tenían accidentes gramaticales (adverbios, preposiciones y conjunciones), por lo que las gramáticas se reducían a poco más que a proporcionar la lista de este tipo de palabras, ordenadas por criterios más o menos rigurosos de naturaleza semántica. La característica formal (variabilidad / invariabilidad) era suficiente para diferenciar estos dos grandes bloques de palabras.

La palabras indeclinables se distinguían entre sí por criterios funcionales: el adverbio, frente a las otras partículas, tenía como función propia la de modificar al verbo como el adjetivo modifica al sustantivo.

Una vez identificada esta clase de palabras por su forma (frente a las palabras declinables) y por su función (frente al resto de las palabras indeclinables), se establecen las categorías adverbiales de lugar, tiempo, modo, afirmación, negación, duda, cantidad, etc., siguiendo criterios exclusivamente semánticos.

La lectura detenida de las gramáticas antiguas de nuestra lengua nos permite comprender cuál ha sido el proceso de formación de la teoría gramatical sobre el adverbio. 
4.1. Nebrija hereda la tradición gramatical latina ${ }^{13}$, recogida en sus Introductiones Latinae ${ }^{14}$, y la adapta a la lengua castellana en su Gramática de la lengua castellana ${ }^{15}$ :

Aduerbium est pars orationis indeclinabilis quae addita uerbo significationem eius aut complet, aut mutat, aut minuit. [...] Hoc enim perficit aduerbium uerbis et participijs adiunctum quod adiectiua nomina substantiuis addita.

El adverbio es una de las diez partes de la oración, la cual añadida al verbo, hinche, o mengua, o muda la significación de aquél [...] I llama se adverbio por que común mente se junta \& arrima al verbo, para determinar alguna qualidad en él, assí como el nombre adjectivo determina alguna qualidad en el nombre substantivo.

Ya desde el principio, recoge Nebrija la posiblilidad que tiene la lengua española de construir adverbios-palabra y adverbios-locución: «Otras muchas maneras ai de adverbios, que se dicen en el castellano por rodeo». Es decir, ya contempla la existencia de las locuciones adverbiales, unidades pluriverbales que tienen el valor de adverbios.

Es llamativo el hecho de que no centre Nebrija su atención en la invariabilidad del adverbio, sino en su función de modificador del verbo; el gramático andaluz no lo dice de manera expresa, pero, probablemente, tenga en cuenta que, en castellano, la variablilidad no es un rasgo obligatorio en los nombres (lunes, martes, tesis, crisis) ni en los pronombres (algo, alguien, nada, nadie). Este hecho tiene trascendencia en la teoría gramatical española del Siglo de Oro, porque los gramáticos de esta época repiten, con muy ligeras variaciones, la definición nebrisense: el adverbio es, fundamentalmente, un modificador verbal ${ }^{16}$. Las menciones a la invariablilidad de los adverbios se hacen siempre de manera marginal, y por parte de los autores de segunda fila: es el caso de la Útil y breve institutión ${ }^{17}$, donde el estudio del adverbio se incluye en un capítulo que lleva por título «De quatuor partibus orationis indeclinabilibus»; de Sanford ${ }^{18}$, quien titula el capítulo donde trata el adverbio «Of particles, the undeclinable parts of speech, and first of adverbs»; o de Doergangk ${ }^{19}$,

13 Toma su definición de Donato, De partibus orationis ars minor (Keil, IV, 362): «Adverbium quid est? Pars orationis, quae adiecta verbo significationem eius explanat atque inplet».

14 Antonio de Nebrija, Introductiones latinae [1481], Salamanca. Edición facsimilar, Salamanca, Universidad de Salamanca, 1981.

15 Antonio de Nebrija, Gramática de la lengua castellana [1492], estudio y edición de Antonio Quilis, Madrid, Editora Nacional, 1981, pág. 197.

16 Vid. Antonio Ramajo Caño, Las gramáticas de la lengua castellana desde Nebrija a Correas, Salamanca, Universidad de Salamanca, 1987, págs. 185-186.

17 Vtil y breve institvtión para aprender los principios y fundamentos de la lengua hespañola, Lovaina, 1555; ed. facsimilar y estudio de A. Roldán, Madrid, C.S.I.C., 1977, pág. 103.

18 J. Sanford, An entrance to the Spanish tongue, London, Printed by Th. Haueland, 1611, pág. 43. Edición electrónica, Clásicos Tavera, Antiguas gramáticas del castellano.

${ }^{19}$ Henricus Doergangk, Institutiones in linguam hispanicam..., Coloniae, Imprimebat Petrus a Brachel, 1614, págs. 265-295. Edición electrónica, Clásicos Tavera, Antiguas gramáticas del castellano. 
quien trata el adverbio en unas páginas bajo el epígrafe de «De partibus indeclinabilibus». Los únicos que incluyen la invariabilidad del adverbio en la definición de esta categoría son Juan de Luna ${ }^{20}$, quien define la categoría como «El adverbio es una dicción que aumenta o disminuye la significación del verbo y no se declina»; y Texeda ${ }^{21}$, quien proporciona la siguiente definición: «El aduerbio es vna parte de la oración indeclinable, la qual ordinariamente va con el verbo y, algunas veces, con el nombre, ansí sustantiuo como adgetiuo, determinando su significación de diuersas suertes».

4.2. La gramática del siglo XVIII mantiene este distinto criterio que se observa en los textos del Siglo de Oro. Unos autores reconocen como características definitorias de la categoría adverbial, tanto la invariabilidad como la incidencia sobre el verbo, como son Martínez Gómez-Gayoso ${ }^{22}$, San Pedro ${ }^{23}$, Muñoz y Álvarez ${ }^{24}$, etc.

En cambio, otros no tienen en consideración la invariabilidad del adverbio. Así, Jovellanos ${ }^{25}$, quien define el adverbio tan sólo por su capacidad de determinar o modificar al verbo, al adjetivo o a otro adverbio. Lo mismo hacen Castrillo $^{26}$, Balbuena y Pérez ${ }^{27}$ y De Cristóbal y Jaramillo ${ }^{28}$.

20 Juan de Luna, Arte breve y compendiossa para prender a leer, escreuir, pronunciar y hablar la lengua española, Londres, por Juan Guillermo, 1623. Edición electrónica, Clásicos Tavera, Antiguas gramáticas del castellano.

21 Jerónimo de Texeda, Gramática de la lengua española, à Paris, chez Nicolas Bourdin, 1619, pág. 272. Edición facsimilar de Juan M. Lope Blanch, México, UNAM, 1979.

22 B. Martínez Gómez-Gayoso, Gramática de la lengua castellana reducida a breves reglas... Madrid, en la imprenta de D. Gabriel Ramírez, 1769, pág. 251 (edición electrónica, Clásicos Tavera, Antiguas gramáticas del castellano): «El adverbio es una parte indeclinable de la oración que se junta al verbo y a otras partes afirmando o negando, aumentando, disminuyendo o mudando la significación de la oración»

23 Benito de San Pedro, Arte del romance castellano, II, Valencia, en la imprenta de Benito Monfort, 1769, págs. 79-80 (edición electrónica, Clásicos Tavera, Antiguas gramáticas del castellano): «El adverbio es una voz indeclinable que se ayunta regularmente al verbo para expresar algún modo suyo o circunstancia. [...] Por lo que de ordinario acrecientan, menguan o mudan la significación del verbo. [...] Aunque de ordinario el adverbio modifica al verbo, se junta también no pocas veces al nombre adjetivo y al participio. [...] Los adverbios son invariables, esto es, no tienen género, número, caso, modo o personas»

24 A. Muñoz Álvarez, Gramática de la lengua castellana ajustada a la latina, Sevilla, en la imprenta de Vázquez y viuda de Hidalgo, 1793, pág. 111.

25 Gaspar M. de Jovellanos, Curso de humanidades castellanas, [s.d.], Biblioteca de Autores Españoles, Madrid, Rivadeneyra, 1858, pág. 112. Edición electrónica, Clásicos Tavera, Antiguas gramáticas del castellano.

26 P. Castrillo, Cartilla de la lengua castellana; método breve y fácil para poder ser gramático... Madrid, por Pantaleón Aznar, 1787, pág. 55.

27 J. Balbuena y Pérez, Arte nuevo de enseñar niños y vasallos a leer, escribir y contar las Reglas de Gramática y Orthografía castellanas..., Santiago, por D. Ignacio Aguayo, 1791, pág. 60.

${ }^{28}$ G. A. de Cristóval Jaramillo, Arte nuevo de ortología, gramática castellana, ortografía y calografía..., Toledo, por los herederos de Nicolás de Almazano, 1793, pág. 40; Curso de Gramática castellana en solos ochenta días, Madrid, en la oficina de D. Gerónimo Ortega, 1798, pág. 22. 
La misma Gramática académica, en sus primeras ediciones, refleja esta distinta consideración de la categoría: en la primera edición ${ }^{29}$, se define el adverbio como: «una palabra que se junta al verbo para modificar y determinar su significación». Sin embargo, a partir de la cuarta edición ${ }^{30}$, la primera que introduce cambios respecto a la de 1771 , ya se hace mención a la invariabilidad del adverbio: «Adverbio es una parte indeclinable de la oración que se junta al verbo para modificar su significación».

4.3. El siglo XIX presenta una situación peculiar ${ }^{31}$. Por una parte están los gramáticos influidos por la tradición, que fijan la doctrina gramatical del adverbio como la parte invariable de la oración que modifica al verbo, al adjetivo y, a veces a otro adverbio. Así lo vemos en Torío de la Riva ${ }^{32}$, Calleja ${ }^{33}$, Noboa ${ }^{34}$, Salleras ${ }^{35}$, Commelerán ${ }^{36}$ y Díaz-Rubio ${ }^{37}$; hay que tener en cuenta que otros autores, como Narciso Herranz ${ }^{38}$, Salvá ${ }^{39}$ y de Miguel ${ }^{40}$, no hablan de la invariabilidad del adverbio al definir esta categoría, pero, cuando reflexionan sobre las clases de palabras, incluyen el adverbio entre las partículas indeclina-

29 Real Academia Española, Gramática de la lengua castellana, Madrid, por D. Joachín de Ibarra, 1771, pág. 186. Edición facsímil y estudio de R. Sarmiento, Madrid, Editora Nacional, 1984.

${ }^{30}$ Real Academia Española, Gramática de la lengua castellana. $4^{\mathrm{a}}$ ed. corregida y aumentada. Madrid, Viuda de Ibarra, 1796, pág. 230.

31 Para el conocimiento del adverbio en los últimos años del siglo XVIII y primeros del XIX, es imprescindeble el estudio de José J. Gómez Asencio, Gramática y categorías verbales en la tradición española (1771-1847), Salamanca, Universidad de Salamanca, 1981, págs. 218-237.

32 T. Torío de la Riva, Compendio sacado de la gramática castellana, Mallorca, en la oficina de Buenaventura Villalonga, 1811, pág. 27.

33 J. M. Calleja, Elementos de gramática castellana, Bilbao, por Pedro Antonio de Apráiz, 1818, pág. 89. Edición electrónica, Clásicos Tavera, Antiguas gramáticas del castellano.

34 A. M. de Noboa, Nueva gramática de la lengua castellana según los principios de la filosofía, Madrid, Imprenta de D. Eusebio Aguado, 1839, pág. 171. Edición electrónica, Clásicos Tavera, Antiguas gramáticas del castellano. Hay que tener en cuenta la observación que hace Gómez Asencio (Gramática y categorías verbales en la tradición española... op. cit., pág. 222) respecto a la teoría gramatical sobre el adverbio de Noboa: la equivalencia adverbio $=$ preposición + régimen es el rasgo único, esencial y caracterizador de este tipo de palabras.

35 M. Salleras, Gramática razonada de la lengua española, Segovia, Imprenta de Pedro Ondero, 1876, pág. 102. Edición electrónica, Clásicos Tavera, Antiguas gramáticas del castellano.

36 F. A. Commelerán y Gómez, Gramática comparada de las lenguas castellana y latina, $2^{\mathrm{a}}$ ed., Madrid, Agustín Jubera, 1897, pág. 247.

37 M. Díaz-Rubio y Carmena, Primera gramática española razonada, $9^{\mathrm{a}}$ ed., vol. I. Madrid, Librería editorial de Bailly-Bailliere e hijos, 1900, pág. 396.

38 D. N. Herranz, Elementos de gramática castellana, Madrid, en la Imprenta que fue de Fuentenebro, 1815, págs. 6 y 59.

39 Vicente Salvá, Gramática de la lengua castellana que ahora se habla, 9a ed., Valencia, Imprenta de José Ferrer de Orga, 1852, págs. 10 y 92.

40 Raimundo de Miguel, Gramática hispano-latina, teórico-práctica para el estudio simultáneo de las lenguas latina y castellana comparadas, 9a edición, Madrid, Agustín Jubera, 1868, págs. 5 y 112 . 
bles. Por otra parte hay un grupo de gramáticos que intenta redactar unos textos «razonados», en los que la lógica prime sobre la herencia gramatical latina; éstos dan muy poca importancia a la invariabilidad, centrando su atención en la función del adverbio como modificador de modificadores. Así, Bello ${ }^{41}$, Giró y Roma $^{42}$, Fernández Monje ${ }^{43}$ y Herráinz ${ }^{44}$. En estos dos últimos, la importancia de la función sintáctica del adverbio es tan importante que llegan a crear un término nuevo para designar la categoría: modificativos invariables o submodificativos, puesto que modifican a otros modificadores.

4.4. En la tradición académica, encontramos un hecho curioso a este respecto y es que la definición del adverbio incluye la mención a la indeclinabilidad en todas las ediciones de la gramática de la RAE, desde la de 1796 hasta la última de 1931, con la excepción de las ediciones de 1870, 1874 y 1878, en las que se define el adverbio como la «parte de la oración que sirve para modificar la significación del verbo o de cualquier otra palabra que tenga un sentido calificativo o atributivo» ${ }^{45}$.

4.5. Las gramáticas de los siglos XVII, XVIII y XIX coinciden en definir el adverbio como un modificador, pero, con frecuencia, disienten respecto a qué tipo de palabras modifica. Gómez Asencio ${ }^{46}$ expone de manera exhaustiva cuáles son las diferencias que expresan los gramáticos referentes a este tema y de qué manera se crea la asignación al adverbio del oficio de modificador del verbo, del adjetivo o de otro adverbio.

4.6. A lo largo del siglo XX, la Gramática académica ofrece dos definiciones de adverbio. Desde la edición de 1900 a la de 1916, se define como: «una parte indeclinable de la oración que sirve para modificar la significación del verbo o de cualquier otra palabra que tenga un sentido calificativo o atributivo». A partir de la de 1917, y hasta la última edición de 1931 (reimpresa, también, en 1959 y 1962) se repite la definición de adverbio como «la parte invariable de la oración que sirve para calificar o determinar la significación del

41 André Bello, Gramática de la lengua castellana destinada al uso de los americanos, [1857], Madrid, Edaf, 1978, págs. 49 y 54.

42 J. Giró y Roma, Elementos de gramática castellana, Valencia, Imprenta de José Ferrer de Orga, 1852, pág. 206.

43 I. Fernández Monje, Curso elemental de la lengua española, Librería de D. León Pablo Villaverde, 1854, pág. 101. Edición electrónica, Clásicos Tavera, Antiguas gramáticas del castellano.

44 G. Herráinz, Tratado de gramática razonada, Segovia, Establecimiento tipográfico de $\mathrm{F}$. Santiuste, 1885, pág. 18. Edición electrónica, Clásicos Tavera, Antiguas gramáticas del castellano.

45 De las gramáticas académicas que he podido consultar, definen el adverbio como «parte indeclinable de la oración» las ediciones de 1854, 1858, 1865, 1866, 1880, 1883, 1885, 1888, 1890, 1895, 1900, 1901, 1904, 1906, 1908, 1909, 1911 y 1913; y como «parte invariable de la oración» las de 1917, 1920, 1924, 1928 y 1931.

46 J. J. Gómez Asencio, Gramática y categorías verbales en la tradición española..., op. cit., págs. 230-235. 
verbo o la del adjetivo, y a veces la de otro adverbio», que es la más generalizada en los textos gramaticales.

Sin embargo, la revisión de la categoría, impuesta por las nuevas corrientes lingüísticas de corte estructuralista, suponen una crisis tal que el Esbozo de la RAE de 1973 no se atreve, no sólo a dedicarle un capítulo al adverbio, sino que ni siquiera ofrece una definición de esta clase de palabras.

La teoría de los rangos, formulada por Jespersen y reelaborada por Hjelmslev, permite a los gramáticos considerar como adverbios todos los elementos que desempeñan en el discurso una función terciaria; el adverbio es un modificador de modificadores. Especial repercusión en la lingüística de la lengua española tuvo el trabajo de Alarcos ${ }^{47}$, escrito desde un punto de vista funcional, inspirado por las doctrinas glosemáticas de Hjelmslev. En él, mostraba la insuficiencia de la definición académica y proponía considerar el adverbio como una clase funcional de unidades caracterizadas por cumplir la condición de ser signos mínimos y cumplir, sin la adjunción de índices funcionales, la función de aditamento.

Pero lejos de ser una solución definitiva, la dificultad que encuentran los gramáticos de incluir las palabras consideradas adverbios dentro de una clase uniforme de elementos, lleva a éstos a hacer diversas propuestas, todas ellas insuficientes e insatisfactorias, como muestran, por ejemplo, los trabajos de Coello Mesa y Martín Rodríguez ${ }^{48}$ o de Hernando Cuadrado ${ }^{49}$.

Un caso digno de análisis, por su originalidad, es el de la Gramática española de Alcina y Blecua. En esta obra, Alcina dedica el capítulo 4 al estudio del pronombre y del adverbio, aunque, en realidad, cada una de estas categorías tiene apartados claramente diferenciados. En ese capítulo apunta soluciones nuevas, pero no se atreve a una ruptura definitiva con la tradición gramatical. En el análisis de la categoría pronombre, al clasificar los elementos que la componen, propone una clase de «pronombres locativos», incluidos en una clase mayor llamada «indiciales de campo»; estos pronombres locativos se subdividen en «locativos espaciales», donde se incluyen palabras como aquí, acá, ahí, allí, allá, y en «locativos temporales», grupo en el que registran palabras como ahora, entonces, hoy, ayer, anteayer, mañana. Otro grupo de pronombres es el de los «identificativos», incluidos dentro de los «pronombres determinativos»; a estos pronombres identificativos pertenecen palabras como así, sí,

47 Emilio Alarcos Llorach, «Aditamento, adverbio y cuestiones conexas», Estudios de gramática funcional del español, op. cit. Este trabajo fue publicado por primera vez en 1969, en la revista Archivum, 19, 1969.

48 A. M. Coello Mesa, y P. A. Martín Rodríguez, «El adverbio: el problema de su definición...», art. cit.

49 Luis A. Hernández Cuadrado, Gramática del adverbio en español, Madrid, Universidad Rey Juan Carlos-Dykinson, 2006. 
también, no, tampoco ${ }^{50}$. Es decir, este autor considera pronombres palabras que la tradición ha tenido siempre por adverbios. Pero la ruptura no es completa porque, cuando estudia el adverbio y establece sus clases, introduce un tipo de adverbios llamados «pronominales», donde incluye los «locativos espaciales», «locativos temporales» e «identificativos», que había analizado páginas antes como pronombres. Es decir, establece un tipo de palabras que, al mismo tiempo, son pronombres y adverbios; o sea, que estas palabras arriba citadas, en realidad, siguen siendo adverbios. Alcina, influido por la teoría de los rangos de Jespersen, define el adverbio como las «palabras que actúan como términos terciarios con relación a verbos o adjetivos (términos secundarios) y a otros adverbios».

4.7. Los estudios gramaticales, a partir de Alarcos ${ }^{51}$ y Kovacci ${ }^{52}$ amplían el ámbito de alcance del adverbio, ya que no sólo es un modificador de modificadores, sino que también es un modificador oracional. En este sentido, constituye un elemento periférico de la oración. Este tipo de adverbios externos a la oración, con el desarrollo de la gramática del texto, han sido analizados desde otro punto de vista, reconociendo que muchas veces no son simplemente modificadores oracionales, sino enlaces textuales, marcadores discursivos, operadores pragmáticos, etc. ${ }^{53}$ Consecuencia de este interés ha sido la proliferación de estudios centrados en los valores de los adverbios terminados en -mente ${ }^{54}$.

La historia de la gramática nos muestra, por una parte, cuáles son los factores que han motivado el mantenimiento de una categoría gramatical como es la del adverbio; $y$, por otra, pone de manifiesto la enorme heterogeneidad formal, funcional y semántica de los elementos incluidos en dicha categoría.

5. La aceptación, a lo largo de la historia, de que la lengua es la expresión verbal del pensamiento ha condicionado toda la interpretación de los hechos lingüísticos y, por ende, la de los gramaticales. Por ello, la gramática se subordinó a la lógica; las categorías gramaticales se han definido por criterios lógicos, y no lingüísticos. Cuando llegó la revolución del estructuralismo, no

50 Juan Alcina Franch y José Manuel Blecua, Gramática Española, Barcelona, Ariel, 1975, pág. 595

51 Emilio Alarcos Llorach, «Aditamento, adverbio y cuestiones conexas», art. cit., pág. 224.

52 Ofelia Kovacci, «Sobre los adverbios oracionales», Estudios de gramática española, Buenos Aires, Hachette, 1980-81/1986 págs. 163-178.

53 Vid. Ana $\mathrm{M}^{\mathrm{a}}$ Barrenechea, «Operadores pragmáticos de actitud oracional. Los adverbios en -mente y otros signos», VV. AA., Estudios lingüísticos y dialectológicos. Temas hispánicos, Buenos Aires, Hachette, 1979.

54 Ángel López García, «El subsistema semántico de los modificadores adverbiales», Elementos de semántica dinámica, Zaragoza, Pórtico, 1977, § 9.1.; Gramática del español. III. Las partes de la oración, Madrid, Arco/Libros, 1998, págs. 535-565. T. Ma Rodríguez Ramalle, La gramática de los adverbios en -mente o cómo expresar maneras, opiniones y actitudes a través de la lengua, Madrid, Publicaciones de la Universidad Autónoma de Madrid, 2003. 
varió esta consideración de la lengua como elemento subsidiario del pensamiento. Saussure, en el Curso de lingüística general $^{55}$ definió el significado, parte constituyente del signo lingüístico, como el contenido conceptual, dotándolo, pues, de naturaleza extralingüística. Esto tuvo como consecuencia que, años más tarde, cuando la lingüística quiso aplicar con rigor los postulados de la glosemática, la semántica quedó excluida de los estudios lingüísticos porque su contenido no afectaba, en rigor, a la lengua, sino al pensamiento. La disciplina encargada de su estudio debería ser la lógica, y no la lingüística ${ }^{56}$.

Sin embargo, la significación es de naturaleza lingüística y no conceptual. Al significado de una palabra pertenece, siguiendo a Trujillo ${ }^{57}$, «todo lo que ésta transmite, exceptuado lo que provenga del contexto». Esta significación es indefinible; los hablantes nativos la adquieren intuitivamente al aprender a hablar. No tiene sentido decir que primero se aprenden los significantes y a éstos, después, se les une los significados; ni que primero se adquiere el conocimiento de conceptos puros que, más tarde, se expresan por imágenes acústicas. Los hablantes aprenden palabras, signos constituidos directamente tanto por un significante como por un significado, unidos ambos íntima e indisolublemente, y que se identifican con la misma palabra. Esta significación se concreta en los distintos sentidos, dependiendo del contexto en el que la palabra se emplee, o según la situación en la que se use. Por ello, las palabras sólo tienen significación en el seno de la lengua a la que pertenecen.

5.1. Uno de los errores cometidos por la gramática tradicional al clasificar las unidades de la lengua ha sido emplear criterios de naturaleza lógica, y no semántica. Éstos tenían como base la realidad extralingüística, en vez de elementos de la propia lengua. Por eso, se abrió un rayo de esperanza cuando los propios lingüistas estructuralistas creyeron posible una semántica estrictamente lingüística. De entre ellos, fue Coseriu el que propuso caminos más sugerentes para el desarrollo de los estudios semánticos. Distingue Coseriu tres tipos de palabras ${ }^{58}$ : a) las palabras lexemáticas, las que constituyen el léxico de una lengua; b) las palabras categoremáticas o pronominales; y c) las morfemáticas o instrumentales. En cierto modo, la tradición gramatical empleó intuitivamente este criterio, aunque de una manera muy laxa, al clasificar las clases de palabras. Consecuencia de ello es la distinción que desde el principio se estableció entre nombres y pronombres como clases de palabras diferentes. Pero, cuando aplicó este criterio, lo hizo de manera fragmentaria, incompleta e incoherente. La historia de la gramática nos muestra cómo se ha ido aplicando con mayor o

55 Ferdinand de Saussure, Curso de lingüística general, [1915], Buenos Aires, Losada, 1973, pág. 128 .

56 Louis Hjelmslev, Prolegómenos a una teoría del lenguaje, Madrid, Gredos, 1974, pág. 113.

57 Ramón Trujillo, Introducción a la semántica española, Madrid, Arco/Libros, 1988, pág. 65.

58 Eugenio Coseriu, Gramática, semántica, universales, Madrid, Gredos, 1978, pág. 133. 
menor rigor, según determinadas circunstancias. Este ha sido, por ejemplo, el caso de los adjetivos. Con frecuencia se ha agrupado en una sola clases los adjetivos propiamente dichos (los calificativos) con los demostrativos, posesivos, numerales e indefinidos (los determinativos) ${ }^{59}$. En pleno siglo XX, la mayor parte de las gramáticas, como las de Cervera ${ }^{60}$, Padilla ${ }^{61}$, Rafael Seco ${ }^{62}$, Vergés ${ }^{63}$, Alonso Cortés ${ }^{64}$, Marcos Marín ${ }^{65}$, Siguiés ${ }^{66}$, Manuel Seco ${ }^{67}$ y otros, clasifica el adjetivo en dos grupos: los calificativos y los determinativos. Estos últimos se corresponden con las formas adjetivas de los pronombres ${ }^{68}$. Sin embargo, la gramática nunca ha clasificado los sustantivos en dos grupos: los sustantivos léxicos y los sustantivos pronominales; siempre ha diferenciado los sustantivos de los pronombres, como dos clases de palabras distintas.

Con respecto al adverbio, por regla general, la única clasificación ha sido la que agrupaba las palabras incluidas dentro de esta categoría según criterios de significación locativa, de tiempo, modo, cantidad, afirmación, negación, duda, etc., si bien es cierto que, tomando como punto de apoyo la semejanza de relaciones entre adjetivo-sustantivo y adverbio-verbo ${ }^{69}$, algunos gramáticos tomaron la teoría gramatical sobre el adjetivo como base para la del adverbio, de manera que diferenciaron entre adverbios calificativos y adverbios determina-

59 Vid. José J. Gómez Asencio, Gramática y categorías verbales..., op. cit., pág. 148.

60 A. Cervera y Royo, Contestaciones sumarias a los programas de gramática castellana, Valencia, Librería de Matías Real, 1913, pág. 117.

61 Salvador Padilla, Gramática histórico-crítica de la lengua española, Madrid, Sáenz de Jubera, Hermanos, 1915, pág. 34.

62 Rafael Seco, Manual de gramática española, Madrid-Barcelona-Buenos Aires, Compañía Ibero-Americana de Publicaciones, 1973, págs. 41-44.

${ }^{63}$ F. Vergés y Soler, Compendio de gramática castellana, Tarragona, Imprenta de José Pijoán, 1931, págs. 98-103.

64 Narciso Alonso Cortés, Gramática de la lengua castellana, Valladolid, Librería Santarén, 1940, págs. 48-49.

65 Francisco Marcos Marín, Curso de gramática española, Madrid, Cincel-Kapelusz, 1980, pág. 193. Marcos Marín llama adjetivos «connotativos» a los que tienen sustancia semántica predicativa, e incluye en ellos a los calificativos y a los numerales; y «no connotativos» a los que tienen significado ocasional, entre los que cuenta los posesivos, demostrativos, indefinidos y relacionantes.

66 M. Sigüés Subijana, Manual de gramática española, San Sebastián, Editorial Txertoa, 1983, págs. 84-87.

67 Manuel Seco, Gramática esencial del español, Madrid, Espasa-Calpe, 1989, págs. 168-170.

68 Vid. José Roca Pons, Introducción a la gramática, Barcelona, Vergara Editorial, 1960, pág. 177.

69 Ya Nebrija, en sus Introductiones latinae establecía esta comparación: «... Hoc enim perficit aduerbium uerbis et participijs adiunctum quod adiectiua nomina substantiuis addita». No es de extrañar que, a lo largo de la tradición gramatical, se vayan repitiendo ideas como la de Commelerán (1897:248): «Modificando principalmente el adverbio la idea del verbo, podríamos decir de él que es el adjetivo del verbo». La RAE adoptará esta doctrina a partir de la edición de 1917. 
tivos. Así, en la Gramática académica, a partir de la edición de 1917, podemos leer ${ }^{70}$ :

... los adverbios son los adjetivos del verbo y de toda otra palabra que tenga un sentido calificativo o atributivo y que, como el adjetivo, se dividen en calificativos y determinativos. Los primeros califican al verbo y al adjetivo, como éste califica al sustantivo, según puede verse comparando las locuciones comer BIEN y comida BUENA; TRISTEMENTE célebre y TRISTE celebridad. Los segundos determinan al verbo o al adjetivo, como éste determina al nombre; v. gr.: MUY feo y MUCHA fealdad; MUCHOS paseos y paseamos MUCHO.

Sin embargo, en ningún momento se esbozó la idea de que estos dos tipos de adverbios constituyeran, en realidad, dos tipos de palabras categorialmente diferentes.

La distinción de Coseriu es de importancia capital a la hora de realizar una ordenación razonable de las categorías gramaticales. Las tres clases de palabras -lexemáticas, categoremáticas y morfemáticas - constituyen grupos perfectamente diferenciados que no pueden ni deben confundirse. Sus elementos son de distinta naturaleza gramatical y semántica.

5.2. Las palabras lexemáticas constituyen el vocabulario de una lengua; tienen inventarios abiertos y están recogidas en los diccionarios. Estas palabras se deben memorizar y combinar según las leyes de la gramática. Todas ellas tienen una base léxica o lexema que se manifiesta por uno o varios morfos. El lexema puede categorizarse de diferente manera según los morfemas con los que se combine o los sufijos que admita. Así, am-or / am-able / am-ar / amablemente son palabras que tienen el mismo lexema, y por tanto, idéntico significado léxico; sin embargo, tienen distinto significado categorial ${ }^{71}$. Las palabras léxicas pueden presentarse como sustantivos, adjetivos, verbos o adverbios; dicho de otro modo, sustantivo, adjetivo, verbo y adverbio no son más que moldes categoriales de las palabras que poseen significado léxico ${ }^{72}$.

La lengua no siempre dispone de la posibilidad de categorizar un lexema como sustantivo, adjetivo, verbo y adverbio. Así, por ejemplo:

\begin{tabular}{|l|l|l|l|}
\hline \multicolumn{1}{|c|}{ Sustantivo } & \multicolumn{1}{c|}{ Adjetivo } & \multicolumn{1}{c|}{ Verbo } & \multicolumn{1}{c|}{ Adverbio } \\
\hline amor & amable & amar & amablemente \\
\hline papel & papelero & empapelar & $\emptyset$ \\
\hline
\end{tabular}

70 Real Academia Española, Gramática de la lengua castellana. Madrid, Perlado, Páez y Compañía, 1917, pág. 136.

71 Eugenio Coseriu, Gramática, semántica, universales, op. cit., págs. 136-137.

72 Vid. E. Vucheva, «El plano del significado desde la perspectiva abierta por Eugenio Coseriu», Rilce, 22, 2, 2006, pág. 290. 
Las funciones sintácticas que puede desempeñar cada palabra vienen condicionadas por la categoría a la que ésta pertenezca.

El adverbio es, por tanto, una palabra lexemática y, como tal, tiene un comportamiento gramatical determinado en cada lengua histórica. Pero no sólo los adverbios de origen adjetivo o sustantivo pertenecen a esta categoría de palabras léxicas; muchos de los considerados adverbios primitivos son también palabras lexemáticas:

\begin{tabular}{|l|l|l|l|}
\hline \multicolumn{1}{|c|}{ Adverbio } & \multicolumn{1}{c|}{ Sustantivo } & \multicolumn{1}{c|}{ Adjetivo } & \multicolumn{1}{c|}{ Verbo } \\
\hline cerca & cercanía & cercano & acercar \\
\hline lejos & lejanía & lejano & alejar \\
\hline delante & delantal & delantero & adelantar \\
\hline atrás & atraso & atrasado & atrasar \\
\hline tarde & tardanza & tardío & tardar \\
\hline pronto & prontitud & pronto & $\varnothing$ \\
\hline temprano & $\varnothing$ & temprano & tempranear \\
\hline
\end{tabular}

Estos adverbios son palabras cuya base léxica puede tomar forma en cualquiera de los diferentes moldes categoriales, como sucede con otras palabras lexemáticas. Por lo tanto, forman parte del vocabulario de la lengua.

La palabra «adverbio» debería reservarse sólo y en exclusiva para designar estos adverbios léxicos, como se reservan, en la gramática actual, los términos «sustantivo»y «adjetivo» para los sustantivos y adjetivos lexicales.

Estos adverbios pueden admitir derivación y gradación, como los adjetivos.

Los alumnos escuchan atentamente / muy atentamente

Los alumnos hablan bajo / bajito / bajísimo

La facultad está cerca / cerquita / cerquísima

Juan se levanta tarde / muy tarde / tardísimo

Daniel se encuentra bien / mejor / muy bien

Son adverbios que, como los adjetivos, pueden combinarse con el artículo lo en construcciones enfáticas, del tipo:
Me admiró lo guapa que era
Me admiró lo duramente que trabajaba
Me admiró lo lejos que vivía
Me admiró lo temprano que se levantaba
Me admiró lo bien que se encontraba

5.3. Las palabras categoremáticas o pronominales tienen los inventarios cerrados y no pertenecen a lo que se suele llamar «vocabulario», sino que se es- 
tudian en las gramáticas de la lengua. Son palabras que tienen significado, pero éste siempre se concreta en unos sentidos que adquieren su valor designativo por alusión o referencia a un contexto o situación determinados. Como elementos categoremáticos que son, pueden desempeñar las funciones propias de los sustantivos, adjetivos y adverbios (nunca la de un verbo), aunque son categorialmente diferentes de los sustantivos, adjetivos y adverbios léxicos; es decir, hay pronombres sustantivos, pronombres adjetivos y pronombres adverbios.

Hay palabras categoremáticas que están obligadas a desempeñar exclusivamente el papel de sustantivo (yo, mí, me, tú, ti, te, él, ella, ello, le, esto, eso, aquello, alguien, nadie, etc.); otras desempeñan únicamente el papel de adjetivo (los posesivos, los artículos, cuyo); y también las hay que sólo pueden tener el rol de adverbio (conmigo, contigo, consigo, aquí, acá, ahí, allí, allá, ahora, entonces, hoy, ayer, mañana, así, etc.). Pero también existen palabras que, sin variación de forma, pueden desempeñar varias funciones: sustantivo y adjetivo: este, ese, aquel, alguna, ninguna, otro; sustantivo y adverbio: algo, nada, etc.

Algunas palabras categoremáticas, adjuntas al sustantivo, pueden desempeñar la función de actualizar al sustantivo. Son los llamados «determinantes» por la gramática.

Las palabras categoremáticas (pronombres) que tienen función adverbial no admiten ni derivación ni gradación, como lo hacen los adverbios. No puede decirse *muy aquí, *más entonces, *conmiguísimo, etc. ${ }^{73}$

Tampoco pueden ir precedidas por el artículo lo enfático, como era el caso de los adverbios ${ }^{74}$ :

*Me admiró lo aquí que vivía

*Me admiró lo entonces que estudiaba

Los pronombres constituyen una clase de palabras completamente diferente de las palabras lexicales. Nunca pueden considerarse como miembros de la misma clase, por mucho que puedan desempeñar funciones sintácticas idénticas. No son iguales ni formal, ni gramatical (pueden tener morfemas — perso-

73 Aunque bien es cierto que, en alguna norma del español americano, es común el empleo de diminutivos como aquicito, ahorita, etc.

74 Algunas formas pronominales, en cambio, admiten la compañía de un artículo con valor referencial, claramente pronominal (Fco. Javier Satorre Grau, «Revisión del sistema pronominal español», RFE, LXXXII, 3-4, 2002, págs. 369-372), cosa que nunca ocurre con los adverbios:

¿En qué coche vamos, en el mío o en el tuyo?

Lo nuestro no funciona

No quiero este coche, quiero el otro

*No quiero el delicadamente

Pero nunca pueden ir acompañados por el artículo lo en construcciones enfáticas:

* Me admiró lo otro que vivía

* Me admiró lo mío que estudiaba 
na, caso- que las palabras lexemáticas que desempeñan la misma función desconocen), ni semánticamente. No hay nada que autorice a incluir dentro de una misma clase adverbios como delicadamente, hondo o lejos y pronombres como aquí, así o ayer. Aquí es tan adverbio como yo sustantivo.

La posibilidad de combinar adverbios y pronombres en el sintagma demuestra su pertenencia a paradigmas distintos. Combinaciones como aquí cerca o mañana temprano son posibles porque aquí y mañana son palabras que no pertenecen al mismo paradigma que cerca o temprano.

5.4. Finalmente, las palabras morfemáticas o instrumentales funcionan siempre en relación con otras palabras en la estructuración del hablar. Son palabras relacionales, invariables, que establecen nexos entre las otras palabras o entre las unidades de rango superior que éstas forman. Desempeñan papeles de conexión o transposición ${ }^{75}$, enlazando los elementos que conforman un texto; también pueden ser modalizadores del discurso. Hablando en términos de teoría de la relevancia, son elementos de significación procedimental ${ }^{76}$. A este tipo de palabras corresponden las preposiciones, las conjunciones y las partículas discursivas ${ }^{77}$. Muchas palabras que la tradición gramatical solía clasificar entre los adverbios, como sí, no, además, etc., pertenecen a este grupo de palabras morfemáticas. En palabras de Coseriu ${ }^{78}$, «no funcionan de modo inmediato como configuradoras del mundo, sino en relación con otras palabras en la estructuración del hablar». No son palabras léxicas ni palabras pronominales; no desempeñan nunca papeles de sustantivo, adjetivo, verbo o adverbio, ni tienen nunca valor referencial. A este tipo de palabras pertenecen los enlaces textuales, los operadores pragmáticos, los ordenadores del discurso, los marcadores de modalidad, etc.

Con frecuencia encontramos en el discurso adverbios y pronombres que se han convertido en palabras morfemáticas por medio de un proceso de grama-

75 Coseriu (Gramática, semántica, universales, op. cit., pág. 134) incluye el artículo entre las palabras morfemáticas. No estoy de acuerdo con esta postura, seguida por Alarcos y otros gramáticos. El artículo, como demostrativo que ha experimentado un proceso de gramaticalización, conserva, en español, valores referenciales que le permiten ser antecedente de relativo y desempeñar otras funciones propiamente pronominales. El artículo es, en español, una palabra categoremática. La gramaticalización del artículo, es decir, la pérdida de contenido semántico —indicación de lejanía - no supone el cambio de palabra categoremática a palabra morfemática. Véase con más detalle este punto en Fco. Javier Satorre, «Revisión del sistema pronominal español», art. cit.

76 Manuel Leonetti y M. Victoria Escandell, «Semántica conceptual / Semántica procedimental», Actas del V Congreso de Lingüística General, II, Madrid, Arco/Libros, 2004, págs. 1727-1738.

77 Utilizo partícula discursiva en el sentido en el que lo emplean Briz y otros (2008): «Se trata de elementos lingüísticos que guían la interpretación del discurso; con palabras utilizadas en enfoques actuales, tienen un carácter más procedimental que conceptual... Son el resultado de un proceso de gramaticalización; gramaticalmente hablando, antes fueron otra cosa».

78 Eugenio Coseriu, Gramática, semántica, universales, op. cit., pág. 133. 
ticalización que les ha hecho perder todos los valores adverbiales y pronominales que poseían. Es el caso, por ejemplo, de encima, ahora o entonces ${ }^{79}$ en casos como:

No ha estudiado nada y encima quiere que lo aprueben No me dan miedo las serpientes; ahora, con las arañas no puedo

Le aseguro que no estoy copiando. Entonces ¿qué haces con esa chuleta?

Lo mismo podemos decir de palabras como hasta en contextos como:

\section{Murió hasta el apuntador}

Algunas gramáticas ${ }^{80}$ consideran que hasta, en estos casos, es un adverbio por el hecho de que su empleo no se ajusta a los usos propios de una preposición. Sin embargo, si obramos con rigor, hemos de reconocer que se trata de una palaba morfemática, de una partícula empleada como procedimiento de intensificación.

6. Un problema no resuelto todavía por la gramática es el de la categorización de los cuantificadores. La tradición gramatical suele clasificarlos entre los pronombres indefinidos, pero se observa la peculiaridad de que estas palabras, con frecuencia, pueden desempeñar papeles sustantivos, adjetivos y adverbiales. Sin embargo, su valor semántico y su comportamiento gramatical nos hacen dudar de esta adscripción al sistema pronominal español. Las palabras que indican cantidad forman un grupo relativamente numeroso; aquéllas consideradas tradicionalmente como pronombres, como mucho, poco, bastante, demasiado, etc. están en relación paradigmática con adjetivos como abundante, numeroso, copioso, harto, escaso, insuficiente, parco, suficiente, excesivo, y con adverbios como abundantemente, copiosamente, escasamente, excesivamente, medianamente, pasablemente, excesivamente, parcamente, suficientemente, etc. El propio DRAE define los valores adjetivos y adverbiales de MUCHO, como: «adj. Abundante, numeroso, o que excede a lo ordinario, regular o preciso. | 2. adv. c. Con abundancia, en alto grado, en gran número o cantidad; más de lo regular, ordinario o preciso»; y de POCO como: «adj. Escaso, limitado y corto en cantidad o calidad. 3 . adv. c. Con escasez, en corto grado, en reducido número o cantidad, menos de los regular, ordinario o preciso».

${ }^{79}$ M. ${ }^{a}$ Antonia Martín Zorraquino y José Portolés, «Los marcadores del discurso», Gramática descriptiva de la lengua española, 3, Ignacio Bosque y Violeta Demonte (dir.), Madrid, Espasa Calpe, 1999, § 63.3.

${ }^{80}$ Emilio Alarcos Llorach, Gramática de la lengua española, Madrid, RAE, Espasa-Calpe, 1994, pág. 219; Francisco Marcos Marín, Fco. Javier Satorre Grau y María Luisa Viejo Sánchez, Gramática española, Madrid, Síntesis, 1999, págs. 281-282. 
Era una película de poca / escasa calidad

La casa tenía muchos / numerosos desperfectos

Me gusta el coche pero es demasido / excesivamente caro

Dieron una solución bastante / pasablemente satisfactoria al problema

No hay diferencia de comportamiento gramatical ni de valor designativo entre poca y escasa, entre muchos y numerosos, entre demasiado y excesivamente, entre bastante y pasablemente. Son palabras que pertenecen a una clase de elementos de inventarios abiertos. La lengua nos ofrece muchas palabras lexemáticas que pueden servir para cuantificar y que pueden permutarse con estos llamados «pronombres indefinidos, cuantificadores imprecisos» sin que se produzcan cambios en el valor designativo del enunciado resultante. El valor determinante que pueden tener estas palabras cuando desempeñan el papel de adjetivos lo tiene también el resto de los adjetivos que indican cantidad:

Muchas personas esperaban a los ganadores del campeonato Numerosas personas esperaban a los ganadores del campeonato Fue recibido por las pocas personas que fueron al aeropuerto Fue recibido por las escasas personas que fueron al aeropuerto

Las palabras que han de clasificarse entre los pronombres deben cumplir la condición de constituir una clase cerrada con un número fijo de miembros desprovistos de significado léxico ${ }^{81}$. Mucho y poco, en cambio, forman parte de una clase de palabras de base léxica, que tiene los inventarios abiertos. La base léxica de estas palabras puede categorizarse como sustantivos, adjetivos, verbos o adverbios, como cualquier palabra léxica:

\begin{tabular}{|l|l|l|l|}
\hline \multicolumn{1}{|c|}{ Sustantivo } & \multicolumn{1}{|c|}{ Adjetivo } & \multicolumn{1}{c|}{ Adverbo } & poco \\
\hline $\begin{array}{l}\text { poquedad } \\
\text { poqueza }\end{array}$ & $\begin{array}{l}\text { poco } \\
\text { apocado }\end{array}$ & $\begin{array}{l}\text { apocar } \\
\text { apoquecer }\end{array}$ & mucho \\
\hline $\begin{array}{l}\text { muchedumbre } \\
\text { multitud }\end{array}$ & mucho & $\begin{array}{l}\text { muchiguar } \\
\text { amuchiguar }\end{array}$ & \\
\hline
\end{tabular}

Admiten derivación apreciativa y gradación: poquito, muy poco, poquísimo, muchito ${ }^{82}$, тиу mисho, muchísimo. Además, admiten el artículo lo en construcciones enfáticas, como es normal entre las palabras lexicales:

Puedes imaginar lo mucho que te quiero

Es asombroso lo poco que trabaja

81 Violeta Demonte, «El adjetivo: clases y usos. La posición del adjetivo en el sintagma nominal», Gramática descriptiva de la lengua española, 1, Igancio Bosque y Violeta Demonte (dir.), Madrid, Espasa Calpe, 1999, pág. 136.

${ }_{82}$ Aunque no es frecuente esta forma diminutiva de mucho en la norma estándar peninsular española, las bases de datos CREA y CORDE de la RAE registran numerosos casos de su empleo. 
Bastante tiene su origen en el participio de presente de bastar, verbo de clarísima base léxica; además, ha creado en español una serie de derivados como bastantear, bastanteo y bastantero. Algo parecido se puede decir de demasiado, palabra derivada del sustantivo demasía, que ha dado origen a un verbo como demasiarse. Son claramente palabras lexicales.

7. Un caso especial, dentro del grupo de los cuantificadores en español, es el de la palabra todo. Esta palabra es una de las más complejas de la lengua española. Uno de los factores que contribuyen en mayor medida a esta complejidad es el hecho de que en ella confluyen los sentidos que en latín tenían los términos OMNIS y TOTUS. Esta oposición se conserva en el seno de la misma palabra todo. Por eso, por ejemplo, puedo decir escribo a máquina con todos los dedos, pero no *escribo a máquina con todo el dedo. En otro lugar ${ }^{83}$ me he detenido en el estudio de esta palabra, y creo haber demostrado que, realmente, en español, hay dos todo: un todo, al que, siguiendo el modelo de Alarcos, podríamos llamar todo ${ }_{l}$, adjetivo —es decir, palabra lexemática-, equivalente al latino TOTUS, y un todo $_{2}$, pronombre — palabra categoremática- equivalente a OMNIS. Son signos distintos, no sólo por su contenido semántico, sino también por su comportamiento sintáctico.

Cuando todo, en español, tiene el valor de OMNIS, se comporta como un pronombre; entonces puede formar parte del sintagma nominal como un adyacente (todos los hombres son mortales, todo hombre es mortal) o como núcleo, estableciendo una referencia anafórica a algún elemento nominal previamente nombrado (llevó dulces a los niños pero no hubo para todos). A la significación de conjunto de elementos que componen una colectividad se suele sumar el valor distributivo que ya tenía OMNIS en latín: todos los hombres son mortales $=$ todos y cada uno de los hombres son mortales.

En cambio, cuando todo tiene el valor de TOTUS, se comporta como un adjetivo, relacionado desde el punto de vista semántico con otros adjetivos, como completo, íntegro, entero, etc. Así, un enunciado como: Juan pintó toda la pared tiene un valor designativo equivalente a «Juan pintó la pared entera», «Juan pintó la pared completa». En un enunciado como Juan pintó la pared pero no la pintó toda, el valor anafórico corresponde al pronombre referencial determinado la; toda se comporta como un adjetivo predicativo, como podrían hacerlo otros adjetivos como completa o entera.

Este todo puede modificar a otros adjetivos sin perder sus marcas flexivas. En este sentido, muestra cierta semejanza de comportamiento con determinados adjetivos calificativos que tienen, entre sus opciones funcionales, la posibilidad

${ }^{83}$ Fco. Javier Satorre Grau, «'Todo', ¿adverbio? Estudio de la palabra simple y de las unidades fraseológicas de las que forma parte», Actes du XXV Congrès International de Linguistique et Philologie Romanes, Innsbruck, 2007 (en prensa). 
de modificar a otros adjetivos sin tener, por ello, que perder sus morfemas flexivos de género y número ${ }^{84}$. Es el caso de

Tengo una vecina tonta perdida

A la clase de Juan asisten dos alumnos sordos totales

Tres niños heridos graves al chocar un autobús con un camión

Es indudable la incidencia de los calificativos perdida, totales y graves sobre los adjetivos correspondientes; es evidente su función terciaria. Pero eso no es argumento suficiente para adscribir estas palabras a la categoría de los adverbios. Es necesario admitir que el adjetivo puede desempeñar, en determinadas ocasiones, funciones terciarias de modificación de un adjetivo. Son adjetivos que proporcionan al adjetivo al que acompañan una significación de grado, en este caso, superlativo. Algo parecido sucede con todo. Sólo todo tiene la posibilidad de tener una función terciaria, de incidir sobre un adjetivo.

Varios son los rasgos combinatorios que distinguen el comportamiento de todo ${ }_{1}$ cuando desempeña una función terciaria:

a) Es obligatoria la anteposición de todo al adjetivo; es decir, existe un orden relativo fijo:

Clara despertó toda soñolienta (Quijote I,43)

[Toda soñolienta] constituye una unidad funcional, un mismo sintagma con un orden que no puede variar. En cambio, en un caso como:

$Y$ así se entretenía... escribiendo... muchos versos todos acomodados a su tristeza (Quijote I,26)

todos, que es un pronombre $\left[\right.$ todo $\left._{2}\right]$ que hace referencia anafórica a los versos, puede ocupar distintos lugares en el sintagma: todos acomodados a su tristeza; acomodados todos a su tristeza; acomodados a su tristeza todos.

b) Todo y el adjetivo al que modifica constituyen un único grupo fónico, es decir, no hay pausa entre ellos:

Creyeron los apicarados ministros que la duquesa hablaba de veras $y$, todos confusos y casi corridos, se fueron (Quijote II,32)

Obsérvese el cambio de significación que se operaría en este texto si colocáramos la pausa entre todos y el participio:

Creyeron los apicarados ministros que la duquesa hablaba de veras y todos, confusos y casi corridos, se fueron.

\footnotetext{
${ }^{84}$ Vid. Fco. Javier Satorre Grau, «El adjetivo adjunto del adjetivo», Filología y Lingüística. Estudios ofrecidos a Antonio Quilis, I, Madrid, CSIC / UNED / Universidad de Valladolid, 2005, págs. 629-638.
} 
Cuando [todos confusos] constituye un grupo fónico, es evidente el valor de todos como elemento terciario de ponderación de la confusión de los ministros. Hay dos adjetivos coordinados; cada uno de ellos está modificado por un elemento con función terciaria: todos y casi. En cambio, cuando una pausa separa ambos elementos, es obligatoria la interpretación de todos como un pronombre con función primaria, que hace referencia anafórica a los apicarados ministros, pronombre que está modificado por los adjetivos confusos y casi corridos.

Pero, a pesar de que todo ${ }_{1}$ es un adjetivo, es decir, una palabra lexemática, y puede desempeñar una función terciaria, ello no es suficiente para poder categorizarlo como adverbio, ya que, al conservar sus marcas flexivas, no cumple la condición de la invariabilidad.

8. ¿Es aplicable lo hasta aquí dicho a las locuciones adverbiales?

En la tradición gramatical española, ya desde Nebrija, son frecuentes las observaciones relativas a la existencia en español, tanto de adverbios que son una sola palabra, como de unidades pluriverbales que funcionan como si fueran adverbios, y que son denominadas «adverbios por rodeo», «modos adverbiales», «frases adverbiales», «locuciones adverbiales», etc. ${ }^{85}$. El hecho de que la lengua española sea relativamente parca en adverbios formados por una sola palabra, provoca que, tanto en los textos gramaticales como en los diccionarios, desde muy pronto, se produjera una equivalencia frecuente entre adverbio-palabra latino y adverbio-locución en español ${ }^{86}$. Son normales equivalencias como las siguientes, tomadas de Doergangk ${ }^{87}$ : AliBI. A otra parte; ClAM. A escondidas; Cumulatim. A montones; DiU. Mucho tiempo; ForTassis. Por ventura, puede ser; Libenter. De gana, de buena gana, de grado; PAUlatiM. Poco a poco; Placide. A plazer; RePtAtim. A gatas; Retrorsum. A reculas; Serio. De veras; SERIO, SCIENTER. A sabiendas; STATIM. De golpe; SuPINE. De colodrillo; etc. En todas ellas, el gramático recurre a locuciones porque no encuentra en español una palabra equivalente al adverbio latino.

Las locuciones adverbiales son construcciones fijadas; tienen naturaleza combinatoria, como las construcciones que regula la gramática de la lengua, pero, a diferencia de éstas, se comportan como una palabra; es decir, el hablante tiene que memorizarlas, como hace con los vocablos, y no crearlas, como hace con las frases y oraciones ${ }^{88}$.

${ }^{85}$ Vid. Fco. Javier Satorre Grau, «Las locuciones adverbiales en la lexicografía hispanolatina del siglo de Oro», Actas del VII Congreso Internacional de Historia de la Lengua Española, Madrid, Arco/Libros, 2008, págs. 1125-1136.

${ }^{86}$ José J. Gómez Asencio, «De las locuciones adverbiales, ¿qué se hizo en la tradición gramatical española? », Interlingüística, 14, 2003, pág. 68.

${ }^{87}$ Henricus Doergangk, Institutiones in linguam hispanicam..., op. cit., págs. 121-127.

${ }^{88}$ Ignacio Bosque, «Sobre el concepto de 'lugar común' desde el punto de vista gramatical», Pandora. Revue d'études hispaniques, 1, 2001, pág. 35. 
Un examen atento del conjunto de elementos que la tradición gramatical y lexicográfica española ha incluido en el grupo de las locuciones adverbiales nos permite constatar, también en este caso, la enorme diversidad y heterogeneidad de las unidades agrupadas bajo este epígrafe. Es necesario clasificar estas unidades fraseológicas de manera análoga a como se han clasificado los elementos que se incluían en la categoría «adverbio» en la tradición gramatical española.

Al realizar esta tarea, llama poderosamente la atención el hecho de que sólo las palabras lexicales y las morfemáticas son susceptibles de ser sustituidas por locuciones. Las palabras categoremáticas no admiten esta sustitución. Es decir, locuciones como a brazo partido, de punta en blanco, de bóbilis bóbilis, a hurtadillas, en el quinto pino, etc. tienen un valor equivalente al que desempeñaría, si existiera, un adverbio lexical. Otras, como de todas formas, a todo esto, de todas todas, por cierto, por lo visto, en cambio, sin embargo, en conclusión, etc., son partículas discursivas que funcionan en la lengua de manera análoga a palabras morfemáticas ${ }^{89}$. En cambio, no encontramos ninguna locución que tenga un funcionamiento en el discurso equivalente a un elemento categoremático.

Por lo tanto, y, siendo coherentes con lo anteriormente dicho, se debe reconocer la naturaleza de «locución adverbial» únicamente a aquellas unidades fraseológicas equivalentes a adverbios, es decir, a palabras lexemáticas. Las locuciones que tienen funciones equivalentes a palabras morfemáticas, podrían denominarse —como lo hace Briz— «partículas discursivas».

9. En resumen, las palabras que la gramática española, tradicionalmente, ha solido clasificar como adverbios deben distribuirse en tres clases distintas:

a) Por una parte, en el grupo de los «adverbios», palabras lexicales no flexivas, que tienen los inventarios abiertos y significado léxico, que forman parte del vocabulario de la lengua. A esta clase pertencen los llamados tradicionalmente adverbios de base adjetiva y sustantiva, pero también muchos otros adverbios primitivos que cumplen las condiciones requeridas para formar parte de este grupo. El papel de estos adverbios, con frecuencia, viene desempeñado por unidades fraseológicas que podemos designar como «locuciones adverbiales».

b) Por otra parte, en el grupo de los pronombres, palabras categoremáticas no flexivas, que tienen inventarios cerrados y un significado cuyos sentidos se concretan siempre por referencia a elementos del entorno, de la situación o del contexto. Estos pronombres pueden desempeñar las mismas funciones que los sustantivos, adjetivos y adverbios, pero no pueden identificarse con ellos porque no tienen ni el mismo comportamiento sintáctico ni el mismo modo de significar. La lengua no tiene locuciones que desempeñen una función equivalente a la de los pronombres.

${ }^{89}$ BRIZ, A. y otros, Diccionario de partículas discursivas del español, edición digital en construcción, 2008. http://textodigital.com/P/DDPD/. 
c) Por último, en el grupo de los elementos morfemáticos, palabras gramaticales que sólo existen en relación a otras. No tienen capacidad de desempeñar funciones sintácticas, sino que tan sólo tienen valores procedimentales, de enlaces sintagmáticos, oracionales o textuales, de modalizadores del discurso, operadores pragmáticos, marcadores discursivos, etc. Las unidades fraseológicas que desempeñan estas funciones podemos denominarlas «partículas discursivas».

9.1. Se puede establecer una analogía entre estos tres tipos de palabras y los elementos que emplea la matemática en las siguientes operaciones:

$$
\begin{aligned}
& 2+3=5 \\
& a+b=x
\end{aligned}
$$

En ellas, 2, 3 y 5 son elementos con valor fijo, como los elementos léxicos; $a$, $b$ y $x$ tienen valor, pero éste depende del contexto en el que estos elementos se encuentren, como los elementos categoremáticos; $\mathrm{y}$, finalmente, $+\mathrm{y}=$ son signos que sólo existen en relación a los otros y marcan el tipo de operación, como las palabras morfemáticas. De la misma manera que no tendría sentido, en matemáticas, considerar como pertenecientes a la misma categoría los elementos aritméticos, los algebraicos y los signos indicadores de operación, tampoco en gramática podemos integrar en un mismo paradigma palabras tan diferentes como las lexemáticas, las categoremáticas y las morfemáticas. 
